\title{
Maximum Tolerable Afterload and Afterload Reserve for the Evaluation of Ventricular Performance
}

\author{
Kozo Suma, M.D. and Takayuki Tsujı, M.D.
}

\begin{abstract}
SUMMARY
The concept of a maximum tolerable afterload and an afterload reserve was proposed for evaluating ventricular function. A maximum tolerable afterload was defined as the systolic ventricular pressure during gradual proximal arterial obstruction, at the point where a distal arterial pressure or flow began to fall. An afterload reserve was defined as the difference between a maximum tolerable afterload and a basal afterload.

By using right heart bypass preparations in dogs, a maximum tolerable afterload and an afterload reserve were compared with the ventricular function curve. An improved ventricular function curve was always associated with a greater maximum tolerable afterload and a greater afterload reserve, whereas a depressed function curve with a smaller maximum tolerable afterload and a smaller afterload reserve.
\end{abstract}

\section{Additional Indexing Words :}

Tetralogy of Fallot Right heart bypass Ventricular function curve Frank-Starling mechanism Cardiac reserve Aortic constriction Partial compensation Hypertrophied heart

\begin{abstract}
A
MONG various factors affecting the results of cardiac operations, the most important is whether the repaired heart can propel a sufficient amount of blood to overcome the afterload caused by ventricular outflow stenosis and peripheral vascular resistance. In a total correction of tetralogy of Fallot, for example, the key factor is whether the right ventricle can maintain a normal output postoperatively in the presence of remaining right ventricular outflow obstruction.

From these clinical experiences, attempts were made to evaluate ventricular performance by measuring a maximum tolerable afterload and an afterload reserve of the ventricle. The maximum tolerable afterload of the left ventricle was defined as a systolic left ventricular pressure at the point where aortic blood flow or pressure began to fall in the course of constricting the proximal aorta gradually with a Rumell tourniquet. The maximum tolerable afterload of the right ventricle was defined as a systolic right ventricu-
\end{abstract}

From the Department of Cardiovascular Surgery, Tokyo Women's Medical College Hospital, 2-1-10, Nishiogu, Arakawa-ku, Tokyo 116, Japan.

Received for publication June 6, 1977. 


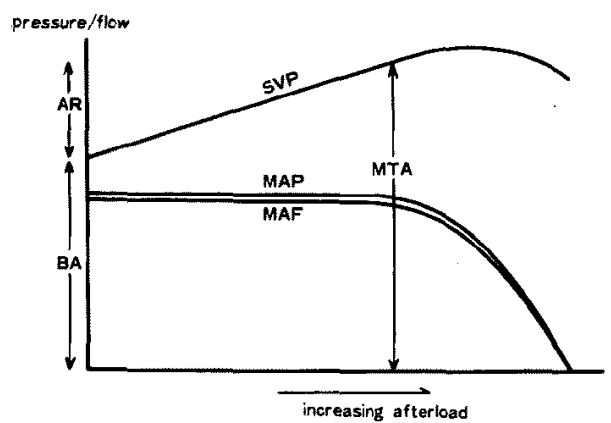

Fig. 1. Diagrammatic representation showing a response to proximal arterial obstruction of systolic ventricular pressure (SVP), mean arterial pressure (MAP), and mean arterial flow (MAF). The maximum tolerable afterload (MTA) was defined as a systolic ventricular pressure at the point where a mean arterial pressure or flow began to fall. The afterload reserve (AR) was defined as a pressure difference between a maximum tolerable afterload and a basal afterload (BA).

lar pressure at the level of pulmonary arterial flow or pressure just below the basal value during gradual constriction of the proximal pulmonary artery. The afterload reserve was defined as the pressure difference between the maximum tolerable afterload and the basal systolic ventricular pressure (Fig. 1).

The present study was undertaken to determine the relationship between left ventricular maximum tolerable afterload and afterload reserve, and the left ventricular function curve, in dog hearts using right heart bypass preparations.

\section{Methods}

Experiments were carried out on 12 mongrel dogs ranging in weight from 14.0 to $17.0 \mathrm{Kg}$. They were anesthetized with sodium pentobarbital $(30 \mathrm{mg} / \mathrm{Kg}$ ) given intravenously. Under positive pressure respiration with $100 \%$ oxygen, the chest was opened through a median sternotomy. A Rumell tourniquet was placed around the aortic root. Another Rumell tourniquet was placed around the proximal anterior descending artery of the left coronary artery. Aortic and left ventricular pressures were measured with pressure transducers. The first derivative of the left ventricular pressure $(\mathrm{dp} / \mathrm{dt}$ ) was obtained with a linear R-G differentiating circuit and recorded together with aortic and left ventricular pressures in a multichannel recorder.

After heparin was administered $(3.0 \mathrm{mg} / \mathrm{Kg})$, right heart bypass was performed. Venous return was diverted to a reservoir and returned to the pulmonary artery through a bubble oxygenator, a heat exchanger and a roller pump. The oxygenator was used because of poor oxygenation due to pulmonary edema which is occasionally observed during right heart bypass preparations. Coronary venous blood was suctioned in the right atrium and returned to the reservoir. 


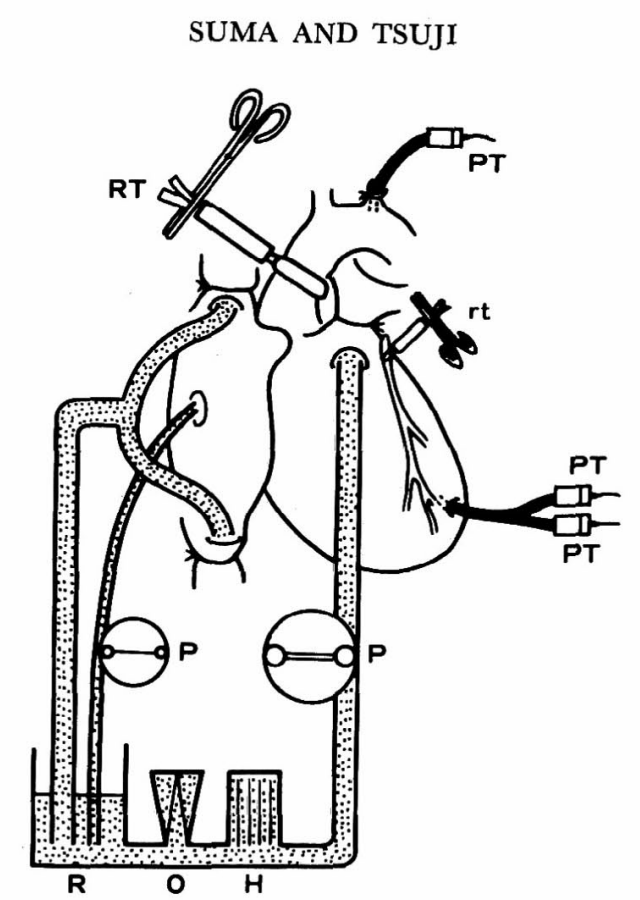

Jap. Heart J.
Tanuary, 1978

Fig. 2. Schematic illustration of the experimental preparation. $\mathrm{P}=$ roller pump, $\mathrm{R}=$ reservoir, $\mathrm{O}=$ oxygenator, $\mathrm{H}=$ heat exchanger, $\mathrm{RT}=$ Rumell tourniquet around aortic root, $\mathrm{rt}=\mathrm{Rumell}$ tourniquet around the anterior descending artery, $\mathrm{PT}=$ pressure transducer.

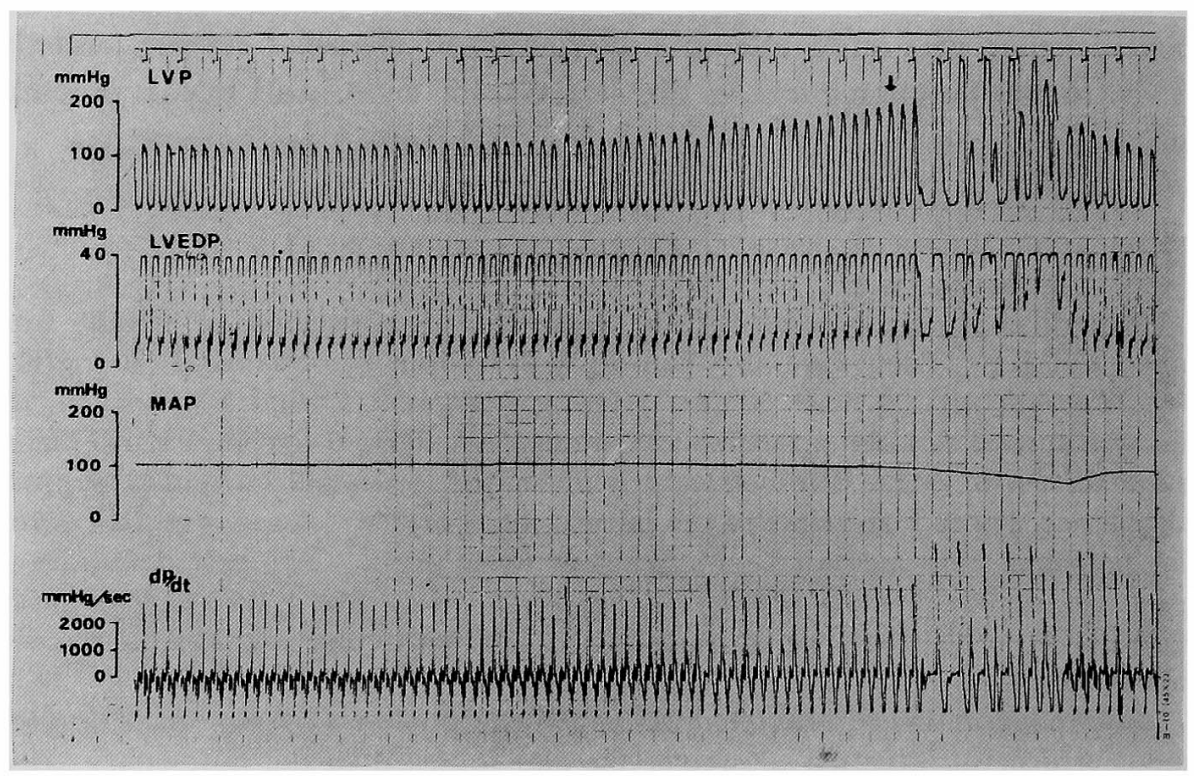

Fig. 3. Representative recording showing the response to proximal aortic obstruction of left ventricular pressure (LVP), left ventricular enddiastolic pressure (LVEDP), mean aortic pressure (MAP), and left ventricular $\mathrm{dp} / \mathrm{dt}(\mathrm{dp} / \mathrm{dt})$. The arrow indicates the point where the maximum tolerable afterload was measured. 
As the initial observation for the control state, a left ventricular function curve was obtained by recording left ventricular end-diastolic pressures at various flow rates. Then, a left ventricular maximum tolerable afterload was obtained at a constant flow rate from the pump by constricting the aortic root gradually (within approximately $30 \mathrm{sec}$ ) with the Rumell tourniquet. The maximum tolerable afterload was measured as a systolic left ventricular pressure at the point where the mean aortic pressure fell $10 \%$ below the basal value. It was assumed that the aortic flow decreased in parallel with the aortic pressure, because the peripheral vascular resistance was considered unchanged during the measurement.

As the second observation for the myocardial ischemic state, left ventricular function curve and maximum tolerable afterload were obtained in the same manner following occlusion of the anterior descending artery with the tourniquet. Then, the tourniquet was released and isoproterenol was administered by drip infusion. After the hemodynamic state was stabilized for several minutes, the final observation for the isoproterenol dripping state was made. The maximum tolerable afterload was determined at the same flow rate from the pump as in the previous observations. The average dosage of isoproterenol administered was $0.14 \mathrm{r} / \mathrm{min} / \mathrm{Kg}$, ranging from 0.06 to $0.24 \gamma / \mathrm{min} / \mathrm{Kg}$.

\section{RESULTS}

1) Left ventricular function curve

For obtaining LV function curve, the flow rate was varied from 70 $\mathrm{ml} / \mathrm{min} / \mathrm{Kg}$ to $130 \mathrm{ml} / \mathrm{min} / \mathrm{Kg}$ in the respective states of each $\mathrm{dog}$.

In the control state, LVEDP was $6.6 \pm 3.7 \mathrm{mmHg}$ at a flow rate of 70 $\mathrm{ml} / \mathrm{min} / \mathrm{Kg}, 8.0 \pm 3.7 \mathrm{mmHg}$ at a flow rate of $100 \mathrm{ml} / \mathrm{min} / \mathrm{Kg}$, and $10.0 \pm 4.1$ $\mathrm{mmHg}$ at a flow rate of $130 \mathrm{ml} / \mathrm{min} / \mathrm{Kg}$. In the myocardial ischemic state,
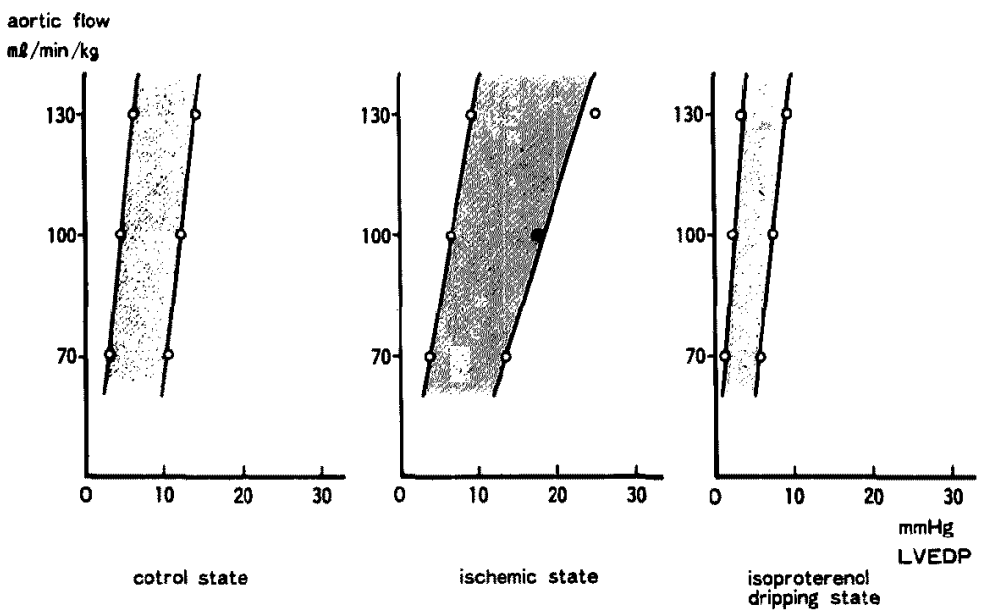

Fig. 4. Distribution areas of left ventricular function curves of the respective states. The closed circles represent one standard deviation on both sides of the average values of left ventricular end-diastolic pressure. 
LVEDP was $8.7 \pm 4.8 \mathrm{mmHg}, 12.1 \pm 5.5 \mathrm{mmHg}$, and $16.6 \pm 7.6 \mathrm{mmHg}$ at the respective flow rates. In the isoproterenol dripping state, LVEDP was 3.9 $\pm 2.6 \mathrm{mmHg}, 5.3 \pm 2.8 \mathrm{mmHg}$, and $6.5 \pm 3.2 \mathrm{mmHg}$ at the respective flow rates. Consequently, $\mathrm{LV}$ function curves shifted from the intermediate zone of the control state to the lower right zone in the myocardial ischemic state, and to the upper left zone in the isoproterenol dripping state.

Fig. 4 shows the ranges of distribution of $\mathrm{LV}$ function curves in the respective states. The closed circles represent one standard deviation on both sides of the average values of LVEDP. While heart rate was $141 \pm 38 / \mathrm{min}$ in the control state, $132 \pm 36 / \mathrm{min}$ in the ischemic state and $164 \pm 38 / \mathrm{min}$ in the isoproterenol dripping state, LV function curves, represented in terms of LVEDP and stroke work, showed similar patterns as those in Fig. 4.

2) LV maximum tolerable afterload

The maximum tolerable afterload was measured, at an identical flow rate from the pump, in the respective states of each dog.

Basal systolic LV pressure, that is, the pressure before aortic constriction, was $112 \pm 24 \mathrm{mmHg}$ in the control state, $115 \pm 18 \mathrm{mmHg}$ in the ischemic state, and $126 \pm 30 \mathrm{mmHg}$ in the isoproterenol dripping state. The maximum tolerable afterload was $193 \pm 34 \mathrm{mmHg}$ in the control state, $166 \pm 28 \mathrm{mmHg}$ in the ischemic state, and $236 \pm 50 \mathrm{mmHg}$ in the isoproterenol dripping state. Thus, LV maximum tolerable afterload was highest in the isoproterenol drip-

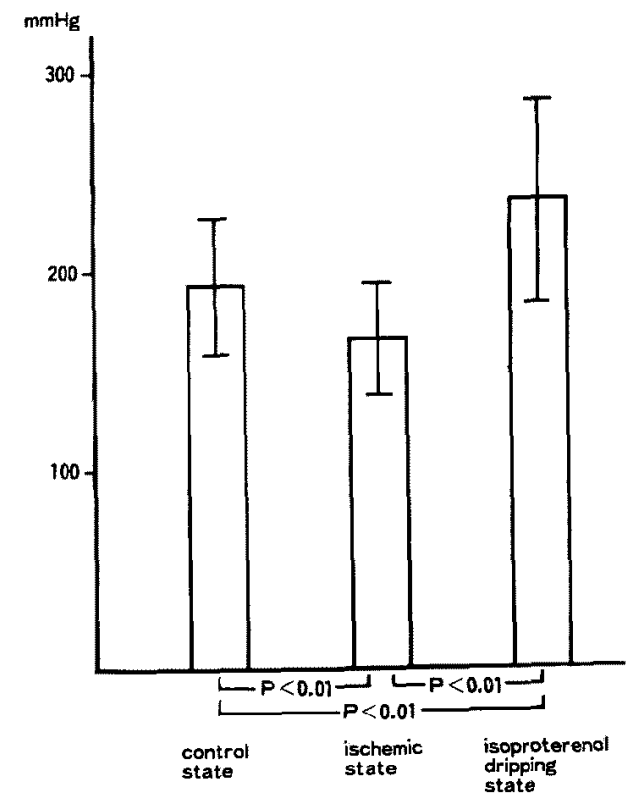

Fig. 5. Average and 1 standard deviation of maximum tolerable afterload of the respective states. Differences between the values were significant. 
ping state and lowest in the ischemic state. The differences between the values of the respective states were significant. Basal value of LVEDP before aortic constriction was $5.9 \pm 4.3 \mathrm{mmHg}$ in the control state, $7.9 \pm 4.5 \mathrm{mmHg}$ in the ischemic state, and $3.8 \pm 3.9 \mathrm{mmHg}$ in the isoproterenol dripping state. LVEDP was elevated in all dogs during aortic constriction. LVEDP was $10.9 \pm 5.4 \mathrm{mmHg}$ in the control state, $17.4 \pm 8.9 \mathrm{mmHg}$ in the ischemic state, and $8.0 \pm 6.1 \mathrm{mmHg}$ in the isoproterenol dripping state, at the time of applying a maximum tolerable afterload to the ventricle.

LV afterload reserve, the difference between a maximum tolerable after-

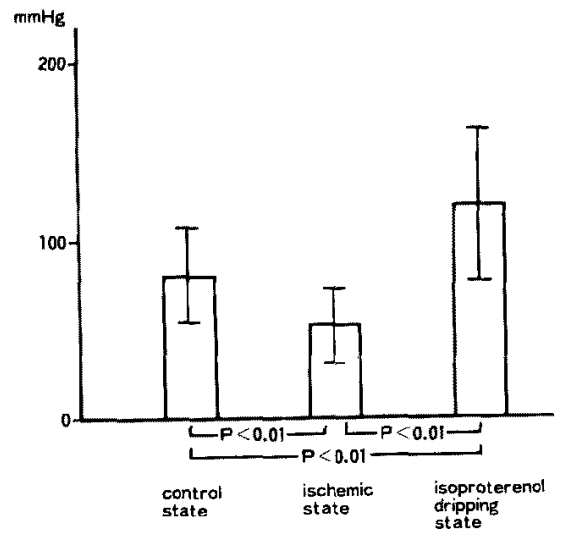

Fig. 6. Average and 1 standard deviation of afterload reserve of the respective states. Differences between the values were significant.

Table I. Values of Maximum Tolerable Afterload and Afterload Reserve of the Respective States

\begin{tabular}{|c|c|c|c|c|c|c|c|}
\hline \multirow{2}{*}{$\begin{array}{l}\text { Dog } \\
\text { No. }\end{array}$} & \multirow{2}{*}{$\begin{array}{l}\text { Flow Rate } \\
(\mathrm{ml} / \mathrm{min} / \mathrm{Kg})\end{array}$} & \multicolumn{2}{|c|}{ Control (mmHg) } & \multicolumn{2}{|c|}{ Ischemic $(\mathrm{mmHg})$} & \multicolumn{2}{|c|}{ Isoproterenol $(\mathrm{mmHg}$} \\
\hline & & M'TA & $\mathrm{AR}$ & MTA & AR & MTA & AR \\
\hline 1 & 86 & 179 & 63 & 175 & 50 & 210 & 95 \\
\hline 2 & 120 & 160 & 35 & 160 & 23 & 225 & 100 \\
\hline 3 & 75 & 170 & 80 & 150 & 40 & 250 & 110 \\
\hline 4 & 80 & 190 & 75 & 160 & 50 & 200 & 90 \\
\hline 5 & 60 & 188 & 100 & 163 & 56 & 250 & 100 \\
\hline 6 & 70 & 275 & 100 & 225 & 75 & 350 & 150 \\
\hline 7 & 86 & 200 & 110 & 155 & 65 & 253 & 170 \\
\hline 8 & 75 & 210 & 115 & 150 & 35 & 215 & 90 \\
\hline 9 & 50 & 210 & 110 & 180 & 70 & 263 & 138 \\
\hline 10 & 43 & 225 & 100 & 210 & 95 & 288 & 163 \\
\hline 11 & 60 & 140 & 55 & 115 & 35 & 160 & 85 \\
\hline 12 & 88 & 167 & 37 & 150 & 25 & 172 & 37 \\
\hline & $74 \pm 20$ & $193 \pm 34$ & $81 \pm 27$ & $166 \pm 28$ & $52 \pm 21$ & $236 \pm 56$ & $119 \pm 43$ \\
\hline
\end{tabular}


load and a basal systolic pressure of the left ventricle, was $81 \pm 27 \mathrm{mmHg}$ in the control state, $52 \pm 27 \mathrm{mmHg}$ in the ischemic state, and $119 \pm 43 \mathrm{mmHg}$ in the isoproterenol dripping state. Although the basal systolic pressure was the highest in the isoproterenol dripping state, the afterload reserve was also the largest. The differences among the values in the respective states were significant. Thus, the results showed that a greater maximum tolerable afterload was associated with a greater afterload reserve.

4) $L V d p / d t_{\max }$

$\mathrm{LVdp} / \mathrm{dt}_{\max }$ was $2,490 \pm 1,740 \mathrm{mmHg} / \mathrm{sec}$ in the control state, $1,830 \pm$ $1,350 \mathrm{mmHg} / \mathrm{sec}$ in the ischemic state, and $3,260 \pm 2,300 \mathrm{mmHg}$ in the isoproterenol dripping state at the flow rate of $100 \mathrm{ml} / \mathrm{min} / \mathrm{Kg}$. The values of the isoproterenol dripping state and the control state were significantly higher than that of the ischemic state. However, the difference between the values of the isoproterenol dripping and the control state was not significant. Similar results were also obtained at the flow rates of $70 \mathrm{ml} / \mathrm{min} / \mathrm{Kg}$ and $130 \mathrm{ml} / \mathrm{min} / \mathrm{Kg}$.

\section{Discussion}

Much knowledge has been accumulated in recent years concerning myocardial mechanics, which has been applied to the intact heart using sophisticated methods. However, the performance of the intact heart can be well understood from the characteristics of pumping capability of the heart. It has been conventionally evaluated as a ventricular function curve.

Efforts have been made to evaluate ventricular performance from a standpoint of ventricular response to afterload.1,2) Although the response of the ventricle to an increase in afterload has been controversial, there is some evidence indicating that the ventricle can pump out an identical amount of blood against relatively wide range of afterload. Sonnenblick and Downing $^{3)}$ reported that over the range of $75-120 \mathrm{mmHg}$ mean aortic pressure, the stroke volume of the left ventricle was independent of aortic pressure. Sagawa $^{4}$ found that cardiac output remained unchanged at an afterload ranging from $30 \mathrm{mmHg}$ to $150 \mathrm{mmHg}$. Taquini and his co-workers ${ }^{5)}$ showed that constriction of the pulmonary artery caused no change of right ventricular output until right ventricular pressure was elevated beyond $60 \mathrm{mmHg}$. Moreover, Ross and Braunwald ${ }^{4}$ showed that infusion of angiotensin in normal human subjects to produce significant increases in systemic arterial pressure had been associated with little change or even an increase in stroke volume. Bugge-Asperheim and $\mathrm{Kiil}^{\mathbf{6}}$ ) reported that cardiac output increased during elevation of aortic pressure at high adrenergic activity, but fell in control state and after propranolol administration. 
In view of these experimental and clinical observations, the authors proposed to assess ventricular performance by determining the maximum tolerable afterload and the afterload reserve of the ventricle. ${ }^{7)}$ Left ventricular response to progressive proximal aortic constriction has 3 phases:1) (1) the phase of complete compensation in which, following transitory elevations of end-diastolic pressure and volume, systolic ventricular pressure is increased and cardiac output is maintained though end-diastolic ventricular pressure and volume return almost to normal; (2) the phase of partial compensation in which systolic ventricular pressure is further increased and cardiac ouptut is slightly diminished while end-diastolic ventricular pressure and volume are increased; and (3) the phase of decompensation in which systolic ventricular pressure reaches a maximum and then decreases as cardiac output falls sharply and end-diastolic ventricular pressure and volume rise progressively.

Maximum tolerable afterload is equal to that afterload which causes partial compensation of the heart. Another experiment by the authors indicated that the ejection fractions measured, while maximum tolerable afterload was applied to the ventricle, were about 0.3 , which was considered to be near the value usually obtained in phase of partial compensation. An elevation of the afterload results in a compensatory rise in the ventricular end-diastolic pressure. As a consequence, the stroke-volume increasing effect of Frank-Starling mechanism ensues, which is balanced by a stroke-volume reducing effect of afterload. When the ventricle is in a higher inotropic state, a greater afterload can be sustained by the ventricle without reduction of stroke volume.

In the present study results were obtained which showed that the maximum tolerable afterload was closely related to the ventricular function curve in non-hypertrophied dog hearts. A greater maximum tolerable afterload indicated an improved ventricular function curve, whereas a smaller maximum tolerable afterload a depressed function curve. This was also the case with afterload reserve: a greater afterload reserve was associated with an improved ventricular function curve. During graded proximal aortic constriction, a greater afterload than the maximum tolerable afterload causes an abrupt fall of distal aortic pressure. The associated hypotension at arterial baroreceptor sites might constitute a stimulus for sympathetic discharge which changes the myocardial contractility. However, this baroreceptor reflex has no significant effect on the values of maximum tolerable afterload, because the hypotension occurs after maximum tolerable afterload is obtained.

An advantage in the use of maximum tolerable afterload over the ventricular function curve to represent ventricular performance is that the maximum tolerable afterload can be expressed quantitatively in numerical terms. 
Ventricular function curves have been used to quantitate cardiac performance of the intact heart. However, it is difficult to quatitate the curves accurately. The curves are usually described vaguely to be located in the upper left or the lower right region, or to be shifted upward to the left or downward to the right depending on ventricular pumping capabilities.

The present study has shown that a greater maximum tolerable afterload is associated with a greater afterload reserve. However, it might not always be the case in diseased hearts. For example, it is conceivable that in the hypertrophied heart, either due to pressure or volume overloading, a greater maximum tolerable afterload is associated with a smaller afterload reserve. The concept that emerges from the study is that cardiac performance should be evaluated from standpoints of both maximum tolerable afterload and afterload reserve. It seems to be important to evaluate cardiac performance from the standpoint of cardiac reserve, especially in hypertrophied hearts.

As the afterload reserve is the difference between the maximum tolerable afterload and the basal afterload, the afterload reserve is influenced by the peripheral vascular resistance, since the basal afterload is a function of the peripheral vascular resistance. The increased peripheral resistance elevates the basal afterload, thereby decreasing the afterload reserve. Therefore, vasodilating drugs seem to have an effect on augmenting the afterload reserve besides increasing the cardiac output in a high resistive vascular state. On the other hand, inotropic substances increase the afterload reserve by augmenting the maximum tolerable afterload.

When a peripheral vasoconstriction is the cause of afterload to the ven-

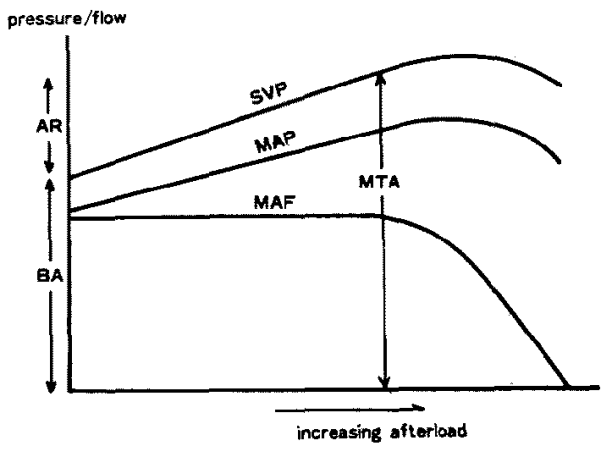

Fig. 7. Diagrammatic representation showing a response to peripheral arterial constriction of systolic ventricular pressure (SVP), mean arterial pressure (MAP), and mean arterial flow (MAF). With increasing afterload to the ventricle, the mean arterial pressure elevates in concordance with the systolic ventricular pressure and dissociates from the mean arterial flow. The maximum tolerable afterload can be defined as the systolic ventricular pressure at the point where the aortic flow begins to fall. MTA=maximum tolerable afterload, $\mathbf{A R}=$ afterload reserve, $\mathbf{B A}=$ basal afterload. 
tricle as in essential hypertension or vasoconstricting drug administration, aortic pressure dissociates from aortic flow, while elevating in concordance with the ventricular systolic pressure as shown in Fig. 7. In such a situation, the maximum tolerable afterload can be determined as the systolic ventricular pressure, where the aortic flow begins to decrease. Thus, the concept of a maximum tolerable afterload and an afterload reserve is applicable to the evaluation of the ventricular performance by afterloading either due to proximal or peripheral arterial vasoconstriction.

\section{REFERENCES}

1. Goodyer AVN, Goodkind MJ, Landry AB: Ventricular response to a pressure load. Left ventricular function curves in intact animal. Circulat Res 10: 885, 1962

2. Ross J Jr, Braunwald $E$ : The study of left ventricular function in man by increasing resistance to ventricular ejection with angiotensin. Circulation 29:739, 1964

3. Sonnenblick EH, Downing SE: Afterload as a primary determinant of ventricular performance. Am J Physiol 204: 604, 1963

4. Sagawa K: Analysis of the ventricular pumping capacity as a function of input and output pressure loads. In: EB Reeve \& AG Guyton (eds), Physical bases of circulatory transport. Regulation and exchange. Saunders, Philadelphia, Chap 9, p 141, 1967

5. Taquini AC, Fermoso JD, Aramendia P: Behavior of the right ventricle following acute constriction of the pulmonary artery. Circulat $\operatorname{Res} 8: 315,1960$

6. Bugge-Asperheim B, Kiil F: Gardiac mechanisms for regulating stroke volume during clevation of aortic blood pressure in dogs. Scand J Clin Lab Invest 30: 23, 1972

7. Suma K: Study on ventricular performance by pressure load. Concept and significance of maximum tolerable afterload and afterload reserve. Shinzo (Heart) 4: 826, 1972 (in Japanese) 